\title{
Seroprevalence and Risk Factors of Toxoplasmosis in Togo
}

\section{Amivi Tété-Bénissan, PhD. Senior Lecturer}

Laboratoire de Physiologie et Pharmacologie des Substances Naturelles, Laboratoire de Recherche Forestière, FDS, Université de Lomé, Lomé, Togo

Mlatovi Dégbé, PhD

Holoud Maman, Doctorant

Laboratoire de Physiologie et de Pharmacologie des Substances Naturelles,

Faculté des Sciences, Université de Lomé, Lomé, Togo

Abiba K. Banla, PhD

Laboratoire de Sérologie, Institut National d'Hygiène Lomé-Togo

Agnon Balogou, PhD. Full Professor

Service de Neurologie du CHU Campus de Lomé, Togo

Kodjo Aklikokou, PhD. Full Professor

Messanvi Gbeassor, PhD. Full Professor

Laboratoire de Physiologie et Pharmacologie des Substances Naturelles

Faculté des Sciences, Université de Lomé, Lomé, Togo

Doi: 10.19044/esj.2018.v14n33p56 URL:http://dx.doi.org/10.19044/esj.2018.v14n33p56

\begin{abstract}
Objectives: Toxoplasmosis is caused by Toxoplasma gondii. 50 to $70 \%$ of African are contaminated and $60 \%$ to $80 \%$ in Togo. This parasitic infection involves disorders in immunocompromised persons and pregnant women. The purpose of this study is to evaluate the seroprevalence of toxoplasmosis and the risk factors of contamination in the Togolese population. Methods: Prospective studies from January 2012 to December 2015 concerned 7076 patients. A survey on the risk factors for Toxoplasma gondii contamination has done. The seroprevalence was monitored by examining serological antibodies $\operatorname{IgG}$ and $\operatorname{IgM}$ using ELISA method. Sampling of 200 excreta of domestic cats were analyzed by coproscopy examinations Results: The average age was 32.61 \pm 6.80 years old. The seroprevalence of $\operatorname{IgM}$ was $2.85 \%$; and for $\operatorname{IgG} 59.7 \%$. IgG were high in men $(67.0 \%$ vs. $58.6 \%, \mathrm{p}<0.0001)$; IgM were high in women $(2.81 \%$ vs. $1.85 \%$, $\mathrm{p}<0.01)$. In this study, we observed $57.49 \%$ immunized subjects. Regarding potential risk factors for contamination, the survey revealed that $80.5 \%$ of subjects consume raw garden produce, $65.4 \%$ non-potable and $8.3 \%$
\end{abstract}


undercooked meat. In cats, $20.5 \%$ of them excreted oocysts of Toxoplasma gondii. Conclusion: The prevalence of the toxoplasmosis was high in the Togolese population because the risks factors were variable and the level of contamination were high too. The country's health authorities, especially for the pregnant women, should install sensitization and prevention programs on the risks of the contamination of toxoplasmosis. The high proportion of the young subjects affected constitutes a socio-economical danger for the country.

Keywords: Toxoplasmosis, seroprevalence, risk factors, Togo

\section{Introduction}

Toxoplasmosis is one of the most common parasitic infections in humans, caused by an Apicomplexa protozoan: Toxoplasma gondii, a ubiquitous parasite of warm-blooded animals. The definitive hosts are felids (Dubey, 2008; Angel et al., 2014). It has a very wide variety of intermediates hosts and can parasitize all types of cells. Horizontal infection generally occurs through the ingestion of raw or undercooked meat that contains cysts (encysted bradyzoites), through the ingestion of contaminated food or in drinking water with oocysts. The transplacental transmission from mother infected occurs during pregnancy (Montoya and Liesenfeld, 2004; Dubey, 2008 ; Dubey et al., 2012; Hammond-Aryee et al., 2014).

In the immunocompetent subjects, toxoplasmosis is asymptomatic in $80 \%$ of cases. However, ganglionic affection with fever, lymphadenopathy and asthenia can be observed. In immunocompromised patients, toxoplasmosis caused life-threatening infections such as encephalitis, lethargy, ataxia, coma, pneumonia, chorioretinitis. Encephalitis toxoplasmosis is the leading cause of death in patients (Webster, 2001; Labalette et al., 2002; Montoya and Liesenfeld, 2004; Dubey and Jones, 2008). The severity of infections is related to the decrease of T-cells and IFN$\gamma$. This involves rapidly proliferating of tachyzoites leading to tissue necrosis (Labalette et al., 2002; Dubey and Jones, 2008; Montoya and Remington, 2008).

Symptoms of infection in pregnant women are rare. However, acute infection can lead the lesions of the placenta and induce serious type of foetopathies. The consequences of congenital infection are spontaneous abortions, stillbirths, premature births and multi-visceral lesions (Pinard et al., 2003; Dubey and Jones, 2008; Montoya and Remington, 2008). The common abortions in patients with toxoplasmosis can be partially attribute to the presence of anti-Cardio-Lipin (A'aiz et al., 2014). The gestational age and the rate of trans placental infection are in correlation and an inverse relationship has been found between the severity of the lesions or clinical 
signs and the gestational age at which maternal seroconversion occurs (Montoya and Remington, 2008; Bamba et al., 2012).

In neonates and infants, Toxoplasma gondii infection causes congenital malformations (hydrocephalus or microcephaly), chorioretinitis, convulsions, intracranial calcification, mental retardation, visual disturbances, learning difficulties (Dubey and Jones, 2008; Uttah et al., 2013). Toxoplasmosis in intermediate hosts has been associated with the development of neurological disorders (Fond et al., 2012; Angel et al., 2014).

Toxoplasmosis diagnosis is mainly based on the presence of antiToxoplasma gondii antibodies (IgG and IgM) in the serum. Several tests can be used as dye test, immuno fluorescent study test, latex agglutination enzyme linked immunosorbent assay (ELISA) (Hamad and Kadir, 2013). It is estimated that one-third of the humanity has this parasitic infection (Montoya and Liesenfeld, 2004; Hammond-Aryee et al., 2014). In Africa, 50\% to $70 \%$ of the populations are infected. The seroprevalence varied widely in different regions of the world according to sanitation level of the population, dietary habits, contacts with cats or contaminated soil and climatic zones. It has been reported that the prevalence is higher $(>60 \%)$ in humid and forest areas, and less than 50\% in dry or desert areas (Millogo et al, 2000 ; Studeničová et al. 2006 ; Dubey et al., 2012; Linguissi 2012; Pangui et al., 2013).

In Togo, the seroprevalence is estimated between $60 \%$ and $80 \%$ (Agbo et al., 1991; Grunitzky et al., 1995, Balogou et al. 2007). Despite the high rate of the toxoplasmosis in Togo, recent data are not available. The aim of this study was to determine the prevalence of Toxoplasma gondii infection in the population for the effective management of the groups that were exposed to high risk of contamination.

\section{Material and methods}

\section{Studies populations and laboratory analysis on prevalence}

A prospective study from January 2012 to December 2015 concerned 7076 patients of all ages (6158 female and 918 male) were oriented for serological tests for detection of Toxoplasma gondii infection.

They were attended to National Institute of Hygiène of Togo, which approved the study.

\section{Collection of specimens}

Blood sample were withdrawn, from patients in the serological laboratory of National Institute of Hygiène (Reference center of medical analyzes of Togo), centrifuged (1000-2000 rpm) and sera were collected kept at $4^{\circ} \mathrm{C}$.

Serological tests were performed by immunoenzymatic method (ELISA): 
-for qualitative detection of anti-Toxoplasma gondii IgM antibodies using Platelia TM Toxo IgM : ref 72841 (BIO-RAD, Marnes la Coquette, France); -for quantitative determination of anti-Toxoplasma gondii IgG antibodies using Platelia TM Toxo IgG: ref 72840 (BIO-RAD, Marnes la Coquette, France).

\section{Information about patients:}

For this prospective study, a paper has been established for each patient from the registers of the laboratory, concerning the : age, sex, profession, level of education, living area, requesting service of the analysis, and tests results.

\section{A survey on the risk factors}

Epidemiological investigation on the risk factors to determine the sources of contamination was performed in the residential areas of the patients. Houses were randomly selected and a total of 300 were visited. The inhabitants were subjected to a structured survey and the questions were about the presence of cats or other animals (dog, mouse ..) in the house, culinary habits, sources of drinking water, food, knowledge and pathologies related to toxoplasmosis.

\section{Animals and fecal sample}

After the interrogation of the subjects, excreta of the cats were collected in the houses. A total of 450 cats (Felis catus) were identified during the study and 200 excreta samples were collected in plastic bags and stored at $4^{\circ} \mathrm{C}$. The excreta samples were analyzed by coproscopy method after enrichment with Willis liquid (saturated solution of $\mathrm{NaCl}$ : density 1.2), by waterline technique. The identification of Toxoplasma gondii oocysts was performed after optical microscope (x10, x40) observation, using reference manual of the laboratory of the National Direction of Livestock of Togo.

\section{Statistical methods}

Data analysis was performed using GraphPad 6.1 software. Quantitative results were expressed by mean \pm standard deviation and in percentage. The different groups were compared by Student test. The correlation coefficients were determined using Pearson test. The frequencies were calculated according to the formulas:

All subjects $=100 X($ Number of Women + Men considered $) /$ Total population $($ Women + Men $)$

Women $=100 X($ Number of Women Considered $) /$ Total Women Population Men $=100 X($ Number of men considered $) /$ Total population of men

The results were considered significant for $p<0.05)$. 
The prevalence $(\mathrm{P})$ has been calculated according to the formula: $P=n / N * 100 ;(n=$ number of positives samples and $N=$ total number of tested samples)

\section{Results}

\section{The study population characteristics}

The sex ratio was 0.15 in favor of women $(87.30 \%)$. The mean age was $32.61 \pm 6.8$ years old (males $34.07 \pm 10.55$ years old; females $32.39 \pm 6.0$ years old). The age groups of 31-45 years old and 16-30 years old were the most represented respectively $62.4 \%$ and $34.6 \%$ of the studied subjects (figure 1).

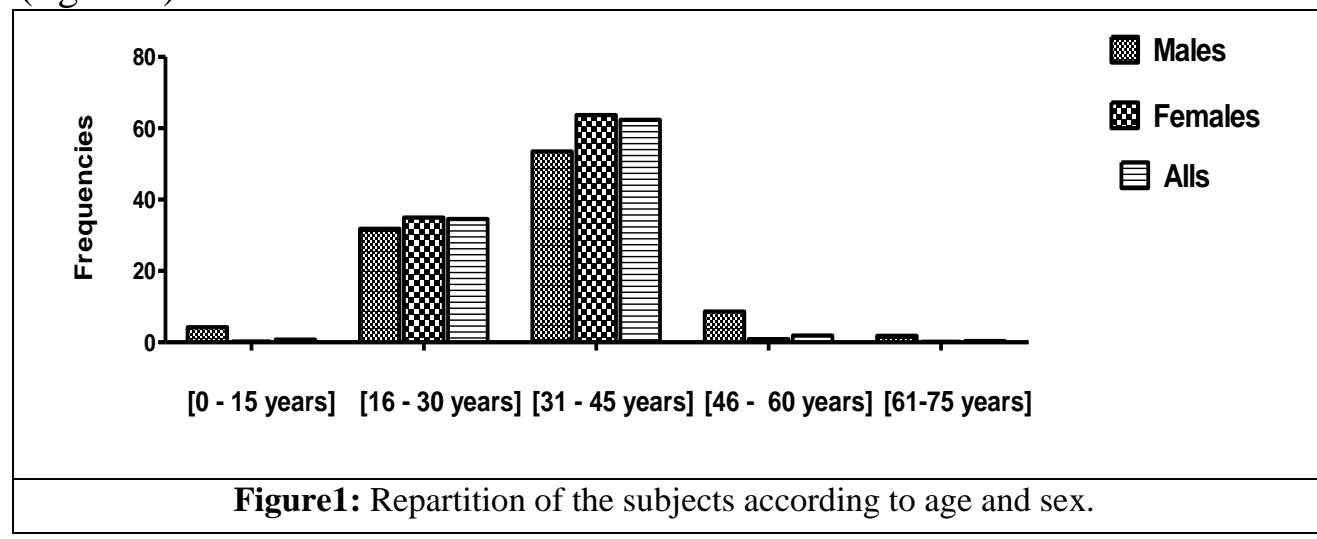

\section{Seroprevalence of IgG and IgM antibodies according to the age}

Considering the age group and its relation with the distribution of seropositive Toxoplasma gondii antibodies (figures $2 \mathrm{a}$ and $2 \mathrm{~b}$ ), we found that the prevalence of IgG seropositivity was high $(>45 \%)$ in all age groups. The age group of $46-60$ years old had the highest percentage $(67.8 \%)$ of positive results, followed by the age group of 16-30 years old (57.8\%) and 31-45 years old $(55.4 \%)$.

For IgM, the highest seropositivity rate of Toxoplasma gondii antibodies was $5.74 \%$, in the age group of 46-60 years old, followed by $2.85 \%$ and $2.23 \%$ in the age groups $31-45$ years old and 16-30 years old respectively. However, it is a lack of $\operatorname{IgM}$ in the age group of 0-15 years old and 61-75 years old. A positive correlation was observed between the age and the prevalence of $\operatorname{IgG}(\mathrm{R}=0.68)$ and $\operatorname{IgM}(\mathrm{R}=0.97)$ in male. In female, the correlation was positive for $\operatorname{IgM}(\mathrm{R}=0.99)$. 


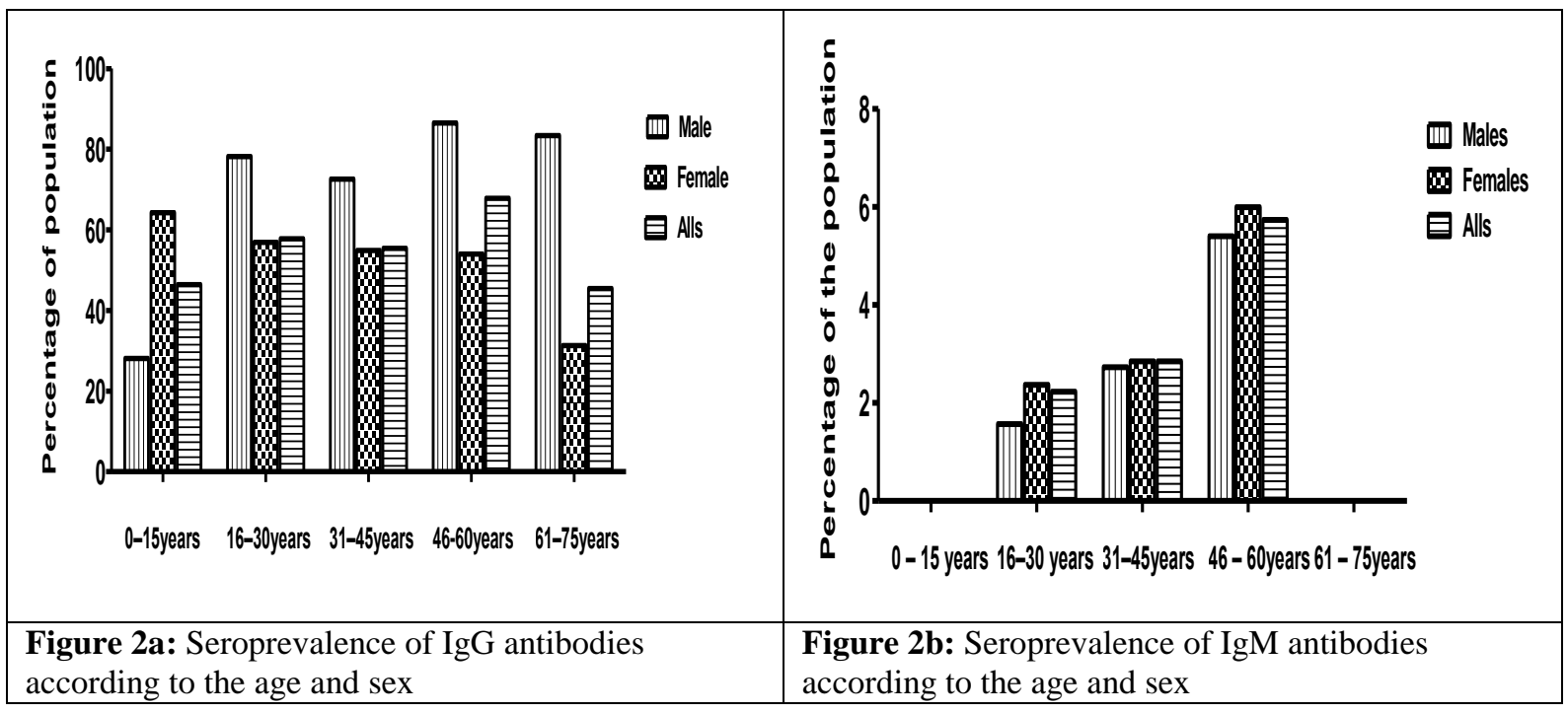

\section{Toxoplasmosis serology in studied population}

Table 1 reveals seroprevalence of toxoplasmosis in 7076 subjects included in the study, 4223 (59.7\%) were seropositive for Toxoplasma gondii antibodies $\operatorname{IgG}$ and 190 (2.69\%) were positive for Toxoplasma gondii antibodies IgM. The frequency of anti-toxoplasmosis $\operatorname{IgG}$ was significantly higher in the males $(67.0 \%$ vs. $58.6 \%, \mathrm{p}<0.0001)$. The rate of antitoxoplasmosis IgM was significantly higher in the female $(2.81 \% \mathrm{vs} .1 .85 \%$, $\mathrm{p}<0.01)$. In this study, we observed 4067 (57.49\%) immunized subjects; females $56.35 \%$ (3469/6158) and males $65.14 \%$ (598/918).

Table 1. Toxoplasmosis serology according to sex

\begin{tabular}{lccc}
\multicolumn{1}{c}{ Antibodies profil } & $\begin{array}{c}\text { Female } \\
(\mathbf{n = 6 1 5 8})\end{array}$ & Male $(\mathbf{n = 9 1 8})$ & Alls (7076) \\
& Number $(\%)$ & Number $(\%)$ & Number $(\%)$ \\
IgM positive & $\mathbf{1 7 3 ( 2 , 8 1 )}$ & $\mathbf{1 7}(\mathbf{1 , 8 5})$ & $\mathbf{1 9 0}(\mathbf{2 , 6 9 )}$ \\
IgG positive & $\mathbf{3 6 0 8}(\mathbf{5 8 , 6 1 )}$ & $\mathbf{6 1 5}(\mathbf{6 6 , 9 9 )}$ & $\mathbf{4 2 2 3}(\mathbf{5 9 , 7})$ \\
IgM positive/IgG negative or IgM & $46(0,75)$ & $0(0)$ & $46(0,65)$ \\
positive/IgG positive (Recent infection or & & & \\
seroconversion) & & & \\
IgM negative/IgG positive (immunized) & $3469(56,35)$ & $598(65,14)$ & $4067(57,49)$ \\
IgM negative /IgG negative(no immunized) & $2516(40,87$ & $303(33,01$ & $2819(39,85)$
\end{tabular}

\section{Results of the survey on the risk factors}

The Analysis of the data collected during the survey revealed that: according to educational status, $88.2 \%$ of the subjects has school education (32.30\% for primary level, $45.4 \%$ for secondary level and $10.5 \%$ for high 
school level). In the study population, $12.2 \%$ had a knowledge of toxoplasmosis.

According to their occupation, $96.5 \%$ of the subjects were often employees, traders or housewives and $3.5 \%$ were women farmers.

Concerning the feed habits, regarding dietary habits, the survey data revealed that $80.5 \%$ of subjects consume raw garden products, $65.4 \%$ nonpotable water and $8.3 \%$ undercooked meat.

\section{Result of fecal samples analysis}

The microscopic observation of the fecal samples of the cats revealed that $20.5 \%$ of them excreted Toxoplasma gondii oocysts.

\section{Discussion}

The aim of this prospective study was to determine the seroprevalence of toxoplasmosis in the Togolese population. The high rates of subjects in the age group of 16 to 45 years old, representing 97\%, confirm the demographic characteristics of developing countries, as Togo, where the majority of the populations is under 40 years old (POPIN).

We found that the seroprevalence for $\mathrm{IgG}$ antibodies was $59.7 \%$ and the one for IgM was $2.7 \%$. The significant high prevalence in men for $\operatorname{IgG}$, ( $\mathrm{p}$ $<0.0001$ ) has already been reported in other studies (Coelho et al., 2003). Antitoxoplasmosis IgG and IgM antibodies, are serological markers of Toxoplasma gondii infection and are synthesized during primary infection (Pinard et al., 2003; Dubey, 2008; Dubey and Jones, 2008; Hamad and Kadir, 2013; Hammond-Aryee et al., 2014). Indeed, by the action of T lymphocytes and cytokines, especially IFN- $\gamma$, parasites encyst in tissues with a weak immune response (brain, muscle, eyes). The antibodies $\operatorname{IgM}, \operatorname{IgE}, \operatorname{IgA}$ were produced during the acute phase of the infection of Toxoplasma gondii. The anti-toxoplasmosis IgG production during the chronic phase providing lifelong protection (Kaneko et al., 2004; Couper et al., 2005; Montoya and Remington, 2008; Dubey et al., 2012). IgM is involved in immune responses by stopping the entry of the parasites into the cells and its intracellular replication (Kaneko et al., 2004; Couper et al., 2005). Therefore, in the immunized women the risk of reactivation of the cysts is reduced. However, in non-immunized women, the risk of infection increases with the age of pregnancy, and the fetus malformations associated with congenital toxoplasmosis increase when the infection occurs earlier in pregnancy. Toxoplasmosis contracted during the first trimester of pregnancy is responsible for spontaneous abortions, stillbirths, premature births and multi- 
visceral lesions (Pinard et al., 2003; Dubey and Jones, 2008; Montoya and Remington, 2008). For this reason, the $40.87 \%$ of non-immunized women in this study have a high risk of contamination (Avelino et al., 2004; HammondAryee et al., 2014). This explains why the screening of toxoplasmosis is a part of health tests advised, but not mandatory in the assessment of pregnancy in many African countries as Togo. In developed countries pregnant women benefit from a special monitoring where Toxoplasma gondii serology is one of the examinations required in early pregnancy (Pinard et al., 2003; AdouBryn et al., 2004; Lopes-Mori et al, 2011; Hamad and Kadir, 2013; Koffi et al., 2015).

In this study, the significant positive correlation, between age and prevalence of $\operatorname{IgG}(\mathrm{R}=0.68)$ in men and $\operatorname{IgM}(\mathrm{R}=0.99)$ in men and women, is explained by the increasing of the risks of infection according to the age and the persistence of infection during the life of patients. This observation is confirmed by the increasing of the seroprevalence from $45 \%$ for age group of 1-15 years old to $67.8 \%$ for age group of 46-60 years old (Garcia et al., 1999; Cantos et al., 2000). 37.5\%

Former studies have shown that seroprevalence varies according to climatic, geographical and socio-economic conditions. The prevalences found in this study are lower than the one found in Central Europe: Slovakia and Czech Republic with 24.2\% and 31.1\% respectively (Svobodova et al., 1998; Studeničová et al. 2006), in Irak with 37.5\% (Hamad and Kadir, 2013). In France the prevalence was $43.8 \%$ (Berger et al., 2009) and in Scotland it was 27\% (William et al., 1981).

In West Africa, a decrease of the prevalence of toxoplasmosis was observed from Senegal with 40.2\% (Faye et al., 1998), Mali, 27\% (Dinkorma et al., 2013) to Mauritania, 14.3\% (Monjour et al., 1983). The seroprevalence of $59.7 \%$ of this study is similar to those observed in Benin, $53.6 \%$ (Rodier et al., 1995), in Burkina, 57.8\% (Millogo et al., 2000; Linguissi et al., 2012), in Ivory Coast, 58.7\% (Koffi et al., 2015). It is lower than the one observed in Nigeria, 75.4\% (Onadeko et al., 1996) and Ghana, 92.5\% (Ayi et al., 2009). In Central and Eastern Africa the prevalence is above 50\% (Bisvigou et al., 2009; Pangui et al., 2013; Yobi et al., 2014).

The seroprevalence of anti-toxoplasma antibodies found in this study is in correlation with the results of previous works in Togo. Comparing these results with the studies done 40 years ago in Togo, we observed no variation in seroprevalences (53\% to $80 \%$ ) in both sexes of all healthy and pregnant women (Agbo et al., 1991; Balogou et al., 2007; Apetse et al., 2015). These results could be explained by the fact that for decades, hygiene and dietary 
habits, food preservation quality have not changed to prevent the contamination by Toxoplasma gondii which infection remains a public health problem in Togo. This confirms our results of the survey on the risks factors of the contamination by Toxopalma gondii that revealed the rate of $80.5 \%$ of subjects that consume raw fruits and vegetables, $65.4 \%$ use non-potable water, $8.3 \%$ eat undercooked meat. In addition, $65 \%$ of the subjects have the contact with cats that $20.5 \%$ of them excreted Toxoplasma gondii oocysts.

The lack of public health schemes to manage the spread of this pathogen places African populations at risk of ongoing and possibly increasing incidence and prevalence, as well as a corresponding increase in mortality and morbidity due to toxoplasmosis (Koffi et al., 2015, Soumana et al., 2016).

\section{Conclusion}

The results of this study revealed that the seroprevalence of toxoplasmosis remains high in the Togolese population. The data observed in this study should allow the country's health authorities to establish sensitization and prevention programs for all age group of the population to explain how to avoid contamination by the food, water and soil. In the houses, the presence of cats (definitive hosts of Toxoplasma gondii) untreated by veterinarians is a permanent danger of reinfection by the inhabitants. For the mainly female population, the program should focus on the risks of fetal diseases and embryopathies related to Toxoplasma gondii infection during pregnancy. An effort should be made to make serological tests available for early detection of infection. Women of childbearing age who are not immunized against Toxoplasma gondii represent a group of high risk of contamination. The high proportion of subjects aged 15-45 years old, the most active and most affected by toxoplasmosis, constitutes a serious danger for the socio-economic development of the country.

In addition, $65 \%$ of the subjects have the contact with cats that $20.5 \%$ of them excreted Toxoplasma gondii oocysts.

Acknowledgments: The authors thank the staff of the National Institute of Hygiene for their technical support and their collaboration.

\section{Conflict of interests}

The authors have no conflicts of interest.

\section{Ethical considerations}

Ethical consideration has been completely observed by the authors. 


\section{References:}

1. A'aiz, N.N., Sultan, B.A., Al-Fatlawi, S.M., Mahmood, A.A. (2014). Association between toxoplasma gondii infection in women and the presence of cardiolipin and phospholipid antibodies. European Scientific Journal, SPECIAL/edition Vol.3; 190-193.

2. Adou-Bryn, K.D., Ouhon, J., Nemer, J., Yapo, C.G., Assoumou, A. (2004). Enquête sérologique de la toxoplasmose acquise chez les femmes en âge de procréer à Yopougon (Abidjan, Côte d'Ivoire. Bulletin de la Société de Pathologie Exotique, 97(5):345-348.

3. Angel, S.O., Figueras, M.J., Alomar, M.L., Echeverria, P.C., Deng B. (2014).Toxoplasma gondii Hsp90: potential roles in essential cellular processes of the parasite. Parasitology; 141(9) : 1138-1147.

https://www.cambridge.org/core/journals/parasitology/article/toxopla sma-gondii-hsp90-potential-roles-in-essential-cellular-processes-ofthe-parasite/FEA49F3900F342B278F70683F7A43CB9

4. Agbo, K., David, M., Amavi-Tete, T., Deniau, M. (1991). Contribution au diagnostic de la toxoplasmose au CHU de Lomé. Bulletin de la Société de Pathologie Exotique, 84, 659-664.

5. Apetse K,Niobe D, Kombate D, Kumako V, Guinhouya K, Assogba $\mathrm{K}$, Balogou A, Grunitzky E. opportunistic infections of HIV/AIDS in a neurological unit in Togo. African Journal of Neurological Sciences 2015; 33(2): 34-40.

6. Avelino, M.M., Campos, D.J., Parada, J.B., Castro, A.M. (2004). Risk factors for Toxoplasma gondii infection in women of childbearing age. The Brazilian Journal of Infectious Diseases, 8(2):164-174.

7. Ayi, I., Edu, S.A., Apea-Kubi, K.A., Boamah, D., Bosompem, K.M., Edoh, D. (2009). Sero-Epidemiology of Toxoplasmosis Amongst Pregnant Women in the Greater Accra Region of Ghana. Ghana Medical Journal, 43(3): 107-114.

https://www.ncbi.nlm.nih.gov/pmc/articles/PMC2810244/pdf/GMJ43 03-0107.pdf

8. Balogou, A., Volley, K., Belo, M., Amouzou, M., Apetse, K., Kombate, D., Grunitzky, E. (2007). Mortalité des patients VIH positifs dans le service de Neurologie du CHU-Campus de Lomé-Togo. African Journal of Neurological Sciences, 26: 95-101.

9. Bamba S., Some, A., Chemla, C., Geers R., Guiguemde T.R., Villena, I. (2012). Analyse sérologique de la toxoplasmose pergravidique: évaluation des risques et perspectives du dépistage prénatal au centre hospitalier universitaire de Bobo Dioulasso au Burkina Faso Pan African Medical Journal, 1937-8688

[http://www.panafrican-med-journal.com/content/article/12/43/full/]

10. Berger, F., $\quad$ Goulet, V., $\quad$ Le Strat, Y., $\quad$ Desenclos, J.C. (2009). 
Toxoplasmosis among pregnant women in France: risk factors and change of prevalence between 1995and 2003. Revue Epidémiologique de Santé Publique, https://doi.org/10.1016/j.respe.2009.03.006

11. Bisvigou, U., Mickoto, B., Ngoubangoye, B., Tsonga, S.M., Akue, J.P., Nkoghe, D. (2009). Séroprévalence de la toxoplasmose dans une population rurale du Sud-Est du Gabon. Parasite, 16(3), 240-242. https://www.parasitejournal.org/articles/parasite/pdf/2009/03/parasite 2009163p240.pdf

12. Cantos, G.A., Prando, M.D., Siqueira, M.V., Teixeira, R.M. (2000). Toxoplasmosis: occurrence of antibodies anti-Toxoplasma gondii and diagnosis. Revue Association Medical of Brasilia, 46(4):335-341. www.scielo.br/pdf/\%0D/ramb/v46n4/3667.pdf

13. Coelho, R.A., Kobayashi, M., Carvalho Jr, L.B. (2003). Prevalence of IgG antibodies specific to Toxoplasma gondii among blood donors in Recife, Northeast Brazil. Review of Institute of Medicine Tropical of Sao Paulo, 45 (4):229-31.

14. Couper, K.N., Roberts, C.W., Brombacher, F., Alexander, J., Johnson, L. (2005). Toxoplasma gondii-specific immunoglobulin M limits parasite dissemination by preventing host cell invasion. Infection and Immunity, $73(12)$, 8060-8068. http://iai.asm.org/content/73/12/8060.long\#

15. Dégbé M., Tété-Bénissan, A., Maman, H., Kulo, A., Batawui, B., Aklikokou, K., Gbeassor, M. (2018). Epidémiologie de la toxoplasmose au Togo : facteurs de risque dans la capitale et ses agglomérations. International. Journal of Biological and Chemical Science, 12 (1) : 479-490.

16. Dinkorma, T. O., Djimdé A.A., Diallo N., Doumbo, O.K. and Roos, D.S. (2013). Toxoplasma gondii Seroprevalence in Mali. The Journal of Parasitology, 99(2) : 371-374. https://www.jstor.org/stable/41982005

17. Dubey, J.P. (2008). The history of Toxoplasma gondii-the first 100 years. Journal of Eukaryotic Microbiology, 55(6): 467-475.

http://onlinelibrary.wiley.com/doi/10.1111/j.15507408.2008.00345.x/pdf

18. Dubey, J.P., Jones, J.L. (2008). Toxoplasma gondii infection in humans and animals in the United States. International journal for parasitology, 38(11), $1257-$ 1278.http://www.sciencedirect.com/science/article/pii/S00207519080 01100?via\%3Dihub

19. Dubey, J.P., Lago, E.G., Gennari, S.M., Su, C., Jones, J.L. (2012) Toxoplasmosis in humans and animals in Brazil: high prevalence, high 
burden of disease, and epidemiology. Parasitology, 139(11):13751424.

20. Faye, O., Leye, A., Dieng, Y ., Richard-Lenoble, D., Diallo, S . (1998). La toxoplasmose à Dakar. Sondage séroépidémiologique chez 353 femmes en âge de procréer. Bulletin de la Société de Pathologie Exotique, 91 ,249 - 250 .

21. Fond, G., Capdevielle, D., Macgregor, A., Attal, J., Larue, A., Brittner, M., Boulenger, J.P. (2012) Toxoplasma gondii: A potential role in the genesis of psychiatric disorders. Encephale, Elsevier Masson, 2012, epub ahead of print. [http://www.hal.inserm.fr/inserm00750381].http://www.em-consulte.com/article/785899/alertePM.

22. Garcia, J.L., Navarro, I.T., Ogawa, L., de Oliveira, R.C., Kobilka, E. (1999). Seroprevalence, epidemiology and ocular evaluation of human toxoplasmosis in the rural zone Jauguapita (Parana) Brazil. Revue Panam Salud Publica, 6(3):157-63. https://www.ncbi.nlm.nih.gov/pubmed/10517092.

23. Grunitzky, E.K., Balogou, A.K., Vimegnon, Y.A., Agbo, K., Sadko, A., Prince-David, M. (1995).Toxoplasmose cérébrale en milieu hospitalier à Lomé (Togo). Bulletin de la Société de Pathologie Exotique, 88: 22-23.

http://ajns.paans.org/dist/data/2005Vol24No2.pdf

24. Hamad, N.R., Kadir M.A. (2013). Prevalence and comparison between the efficacy of different techniques for diagnosis of Toxoplasma gondii among women in Erbil Province-Iraqi Kurdistan. In 1st Annual International Interdisciplinary Conference, AIIC 2013, 24-26 April, Azores, Portugal - Proceedings, P: 901-908.

25. Hammond-Aryee, K., Esser, M., Van Helden, P.D. (2014). Toxoplasma gondii seroprevalence studies on humans and animals in Africa. South Africa Famers Practice, 56(2):119-12. 25.

26. Koffi, M., Konaté, I., Sokouri, D.P., Konan, T., Ahouty, B., Bosso, J.C. (2015). Seroepidemiology of Toxoplasmosis in Pregnant Women Attending Antenatal Clinics at the Center for Maternal and Child Health Care in Daloa in Ivory Coast. International Journal of Tropical Disease \& Health, 6(4): 125-132. DOI:10.9734/IJTDH/2015/15117.http://www.journalrepository.org/ media/journals/IJTDH_19/2015/Jan/Koffi642014IJTDH15117.pdf

27. Kaneko, Y., Takashima, Y., Xuaun, X., Igarashi, I., Nagasawa, H., Mikami, T., Otsuka, H. (2004). Natural IgM antibodies in sera from various animals but not the cat kill Toxoplasma gondii by activating the classical complement pathway. Parasitology, 128(02):123-129. https://www.ncbi.nlm.nih.gov/pubmed/15029999 
28. Labalette, P., Delhaes, L., Margaron, F., Fortier, B., Rouland, J.F. (2002). Ocular toxoplasmosis after the fifth decade. American journal of ophthalmology, 133(4), 506-515. http://www.ajo.com/article/S0002-9394(02)01324-7/pdf

29. Linguissi, L., Nagalo, B., Bisseye, C., Kagoné, S., Sanou, M., Tao, I., Benao, V., Simporé, J., Koné, B. (2012), Seroprevalence of toxoplasmosis and rubella in pregnant women attending antenatal private clinic at Ouagadougou, Burkina Faso. Asian Pacific Journal of Tropical Medicine, 810-813.

http://www.labiogene.org/IMG/pdf/karou_antibiotique.pdf

30. Lopes-Mori, F.M.R., Mitsuka-Bregano, R., Capobiango, J.D., Inoue, I.T., Reische, E.M.V., Morimoto, H.K., et al. (2011). Programs for control of congenital toxoplasmosis. Revue. Association Medecine Brasilia, 57(5):581-586.

31. Millogo, A., Ki-Zerbo, G., Traore, W., Sawadogo, B., Ouedraogo, I., Peghini, M. (2000). Sérologie toxoplasmique chez les patients infectés par le VIH et suspects de toxoplasmose cérébrale au centre hospitalier de Bobo-Dioulasso (Burkina-Faso). Bulletin de la Société de Pathologie Exotique, 93: 17-19.

http://www.pathexo.fr/documents/articles-bull/T93-1-2057.pdf

32. Monjour, L., Niel, G., Palminteri, R., Sidatt, M., Daniel-Ribeiro, C., et al. (1983). An epidemiological survey of toxoplasmosis in Mauritania. Tropical Geog Medecine, 35:21-24.

33. Montoya, J., Liesenfeld, O. (2004) «Toxoplasmosis». Lancet, 363(9425):19651976.http://www.thelancet.com/journals/lancet/articl e/PIIS0140-6736(04)16412-X/fulltext

34. Montoya, J.G., Remington, J.S. (2008). Management of Toxoplasma gondii Infection during Pregnancy. Clinical Infectious Diseases, 47:554-566.

https://academic.oup.com/cid/article-lookup/doi/10.1086/590149

35. Onadeko, M.O., Joynson, D.H., Payne, R.A., Francis, J. (1996). The prevalence of toxoplasma antibodies in pregnant Nigerian women and the occurrence of stillbirth and congenital malformation. African Journal of Medical Science, 25:331-334.

36. Pangui, L.J., Gbati, O.B., Kamga Waladjo, A.R., Bakou, S.N.(2013). Point sur la toxoplasmose en Afrique de l'ouest et du centre. Revue Africaine de Santé et de Productions Animales, 11 (S) : 29-40. http://www.e-ucad.sn/eismv/2016/07/02/documentation/ PDF

37. Pinard, J.A., Leslie, N.S., Irvine, P.J. (2003). Maternal serologic screening for toxoplasmosis. Journal of Midwifery Womens and Health, 48(5):308-16 [quiz 386]. 
38. POPIN, United Nations Population Information Network : Population et Développement en Afrique, OUA\& $C E A$

http://www.un.org/popin/icpd/conference/bkg/afrique.html [consulté en juillet 2018]

39. Rodier, M.H., Berthonneau, J., Bourgoin, A., Giraudeau, G., Agius, G., Burucoa. (1995) Seroprevalences of Toxoplasma, malaria, rubella, cytomegalovirus, HIV and treponemal infections among pregnant women in Cotonou, Republic of Benin. Acta Tropicalis, 59(4):271277.

40. Studeničová, C., Gabriela, B., Renata, H. (2006). Seroprevalence of Toxoplasma gondii antibodies in a healthy population from Slovakia. European Journal of Internal Medicine, 17: 470-473.

https://www.researchgate.net/publication/6698116_Seroprevalence_o f_Toxoplasma_gondii_antibodies_in_a healthy_population_from_S1 ovakia.

41. Svobodova, V., Literak, I. (1998). Prevalence of IgM and IgG antibodies to Toxoplasma gondii in blood donors in the Czech Republic. European Journal of Epidemiology, 14(8):803-5. https://www.ncbi.nlm.nih.gov/pubmed/9928876.

42. Uttah, E.C., Ajang, R., Ogbeche, J., Etta, H., Etim, L. (2013). Comparative Seroprevalence and Risk Factors of Toxoplasmosis among Three Subgroups in Nigeria. Journal of Natural Science Research, 23-29.

http://www.iiste.org/Journals/index.php/JNSR/article/download/6891 $\underline{16997}$

43. Webster, J.P. (2001). Rats, cats, people and parasites: the impact of latent toxoplasmosis on behaviour. Microbes and infection, 3(12):1037-1045.Article /pii/S1286457901014599?via\%3Dihu.

44. Williams, K.A., Scott, J.M., Macfarlane, D.E., Williamson, J.M., Elias-Jones, T.F., Williams, H. (1981). Congenital toxoplasmosis: a prospective survey in the West of Scotland. Journal of Infection, 3(3):219-29.

45. Yobi, D., Y., Piarroux R., L’Ollivier C., Franck J, Situakibanza H, Muhindo H, Mitashi P, Raquel Andreia Inocêncio da Luz, Van Sprundel M, Boelaert M, Van Geertruyden JP, Lutumba P. (2014). Toxoplasmosis among pregnant women: high seroprevalence and risk factors in Kinshasa, Democratic Republic of Congo. Asian Pacific Journal of Tropical Biomedical 2014; 4(1): 69-74).

https://www.ncbi.nlm.nih.gov/pmc/articles/PMC3819499/pdf/apjtb04-01-069.pdf 